\title{
Mapping mesoscale variability of the Azores Current using TOPEX/POSEIDON and ERS 1 altimetry, together with hydrographic and Lagrangian measurements
}

\author{
Fabrice Hernandez ${ }^{1}$ and Pierre-Yves Le Traon \\ Space Oceanography Group, Collecte Localisation Sateltites, Toulouse, France

\section{Rosemary Morrow} \\ Unité Mixte de Recherche 39 / Groupe de Recherche de Géodésie Spatiale, Toulouse, France
}

\begin{abstract}
The SEMAPHORE mesoscale air/sea experiment was conducted in the AzoresMadeira region from July to November 1993. TOPEX/POSEIDON (T/P) and ERS 1 were flying simultaneously at that time. The main purposes of this paper are to evaluate the estimation of the oceanic mesoscale circulation from the two different sets of altimetric data (T/P and ERS 1) and to compare the results with in situ measurements provided by the SEMAPHORE hydrographic surveys and surface drifters (three expendable bathytermograph conductivity-temperature-depth surveys in a $500-\mathrm{km}^{2}$ box and a set of 47 Lagrangian surface drifters drogued at $150 \mathrm{~m}$ ). Comparisons are carried out through the maps obtained by objective analysis from the four data sets. The mapping accuracy of T/P, ERS 1, T/P and ERS 1 combined, and in situ data is investigated, as well as the sensitivity of the mapping to the correlation functions used. There is a good qualitative agreement between altimetric maps and corresponding drifter and hydrographic maps for the three hydrographic surveys. Correlations are about 0.8 , and the regression fit is about 0.6-0.7; the lower values are due to the smooth climatology used to reference the altimetric maps. The correlation for time differences is better, with regression lines not significantly different from 1, especially when ERS 1 and T/P are combined. T/P mapping is almost as good as ERS 1 mapping, which was rather unexpected since the ERS 1 space-time sampling is better suited for the mesoscale. This may reflect the fact that the signal mapped by the hydrography and drifters does not contain the high frequency/wavenumber components. T/P and ERS 1 combined provide better results, although the improvement is not as large as expected, probably for the same reason.
\end{abstract}

\section{Introduction}

Our knowledge of ocean mesoscale dynamics has been greatly improved by the advent of satellite altimetry. The single-altimeter Exact Repeat Missions (ERMs) of Seasat (see, special issus on Seasat in Journal of Geophysical Research, 87 (C5), 265 pp., 1982, and 88 (C3), 423 pp., 1983 ) and Geosat (see, special section on Geosat in Journal of Geophysical Research, 95 (C3), 2833-3179, 1990) have allowed us to measure the distribution and variance of the mesoscale dynamics in most of the global oceans. A new era of space oceanography has now started with the launching of the European Space Agency (ESA) satellite ERS 1 in 1991 and of the TOPEX/POSEIDON (T/P) mission during the summer of 1992, jointly managed by the Centre National d'Etudes Spatiales (CNES) and the National Aeronautics and Space Agency (NASA). These two missions, llying concurrently after mid-1992, provide complementary data sets. T/P is a highly precise altimetric mission dedicated to the large-scale sea level monitoring [Fu et al., 1994]. ERS 1 is less precise than T/P, but its dense spatial coverage allows us to survey the mesoscale circulation of the ocean [e.g., Wakker et al., 1993].

\footnotetext{
I Also at UMR 39, Groupe de Recherche de Géodésie Spatiale, Toulouse, France.

Copyright 1995 by the American Geophysical Union.

Paper number 95JC02333.

0148-0227/95/95JC-02333\$05.00
}

The combination of T/P and ERS 1 data should thus allow a mapping of surface ocean variability with a high accuracy and an improved spatial and temporal coverage [Le Traon et al., 1995]. However, there are some problems in combining these different altimeter measurements due to their different sampling characteristics and errors. For each individual altimetric mission we need to understand how the sampling and errors affect the measured ocean dynamics before we can usefully combine the data sets.

This paper will focus on evaluating the estimation of the oceanic mesoscale circulation from the two different sets of altimetric data (T/P and ERS 1) and compare the results with two types of in situ measurements provided by the hydrographic surveys and surface drifters of the SEMAPHORE mesoscale air/sea experiment. Comparative studies between altimetric and in situ data have previously been performed with Geosat measurements [e.g., Hallock et al., 1989; Willebrand et al., 1990]. In this study, two-dimensional maps of surface circulation are estimated from each kind of data. By analyzing the maps, one can evaluate the space and time sampling characteristics of the mesoscale variability by the different types of data. By comparing the maps, one can get a better idea of (1) the oceanic content of each type of data and (2) the precision obtained from each type of data in the estimation of the surface circulation.

The SEMAPHORE experiment was conducted in the AzoresMadeira area of the North Atlantic in 1993. The main objective of SEMAPHORE was to analyze the heat and momentum exchange between the atmosphere and the ocean 
[Eymard et al., manuscript in preparation 1995]. The experiment used extensive instrumentation to simultaneously observe the atmosphere and the ocean (two planes, three ships, about 100 drifters or floats, four current meter moorings, etc). The SEMAPHORE in situ instrumental strategy is described in detail by Eymard el al. As part of the experiment, the objective of the mesoscale oceanic circulation investigation was to precisely observe the threedimensional (3-D) oceanic circulation and thermohaline characteristics associated with the Azores front over several months (more than the characteristic decorrelation time). Forty-seven Lagrangian surface drifters drogued at $150 \mathrm{~m}$ were deployed to accurately map the surface geostrophic circulation. Two main expendable bathythermograph conductivity-temperature-depth (XBT/CTD) surveys were performed in a $500 \times 500 \mathrm{~km}^{2}$ box, with a nominal resolution of $30 \mathrm{n}$. mi. $(55.56 \mathrm{~km})$ at 3 -month intervals (July and October-November 1993) (phase 1 and phase 3). An intermediate XBT survey was performed in September 1993 (phase 2). Whenever possible, hydrographic sections were performed along T/P and ERS 1 tracks (see Figure 1). Another central objective of this investigation was to examine how well T/P and ERS 1 altimetric data measure the oceanic mesoscale circulation, which is the subject of this paper. The Azores Current is of particular interest for these comparisons since Geosat altimetric data have already been analyzed here [Le Traon and De Mey, 1994] and compared to in situ data [Stammer et al., 1991; Zlotnicki et al., 1993]. It is also a
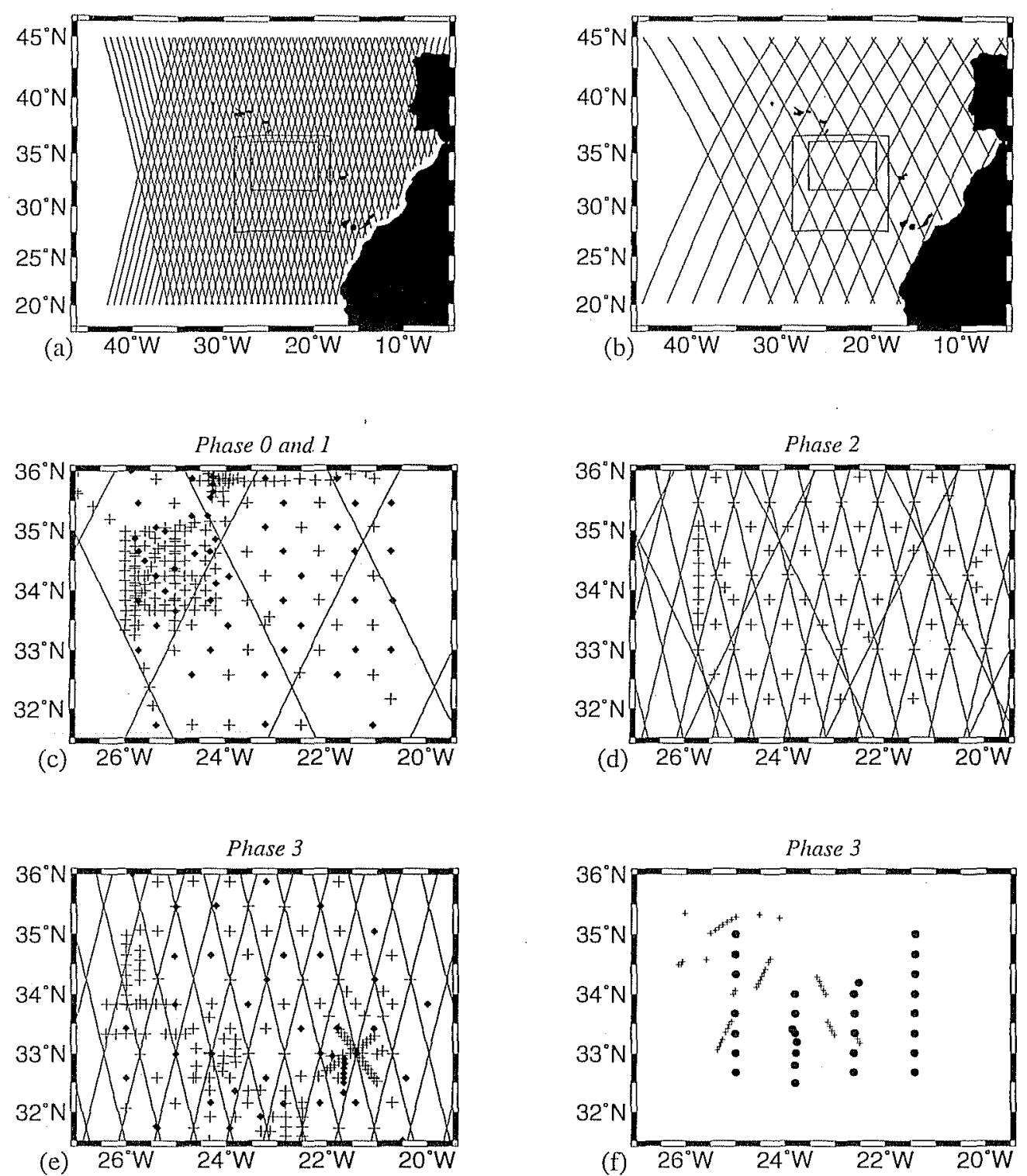

Figure 1. Data distribution during the SEMAPHORE-93 experiment showing (a), ERS 1 and (b) TOPEX/POSEIDON (T/P) groundtracks selected for this study. The larger rectangular area corresponds to the region of surface drifters/altimetric comparisons, and the smaller is the mapping area and also the hydrographic/altimetric comparison domain. Hydrographic data distribution in this area (crosses for expendable bathythermographs (XBTs) and diamonds for conductivity-temperature-depth (CTD) profilers). (c) phase 0 (concentrated on $33-35^{\circ} \mathrm{N}, 24-26^{\circ} \mathrm{W}$ ) and phase 1 surveys, (d) phase 2 XBT survey, (e) phase 3 Service Hydrographique et Océanographique de la Marine (SHOM) survey, with the cross of XBTs centered on $21.5^{\circ} \mathrm{W}$ corresponding to a measurements in a meddy, (f) phase 3, Suroit (crosses concentrated on fronts) and $P r$. Stockmann (circles) surveys. The five T/P and 31 ERS 1 ground tracks are overlaid in figures $1 \mathrm{c}-1 \mathrm{f}$. 
region where the mesoscale activity is slightly higher than in the rest of the eastern North Atlantic basin [e.g., Richardson, 1983; Le Traon, 1991].

The paper is organized as follows. The data (T/P, ERS 1, and SEMAPHORE-93) and processing techniques are described in section 2. Section 3 cliscusses the mapping techniques used in this paper, then emphasizes the influence of each characteristic satellite orbit on the sampling of the oceanic circulation, and finally, gives a brief oceanic description of the mesoscale circulation in the region of the Azores Current, based on maps from summer to fall 1993. Section 4 deals with the comparison of the maps obtained from altimetric data and hydrography. Main conclusions are given in section 5 .

\section{Data and Processing}

\subsection{Altimetric Data}

2.1.1 ERS 1. The ESA ERS 1 satellite was launched in July 1991. The most useful altimetric data for mesoscale oceanographic studies were collected during the 35-day repeat orbit mission. This phase started on April 14, 1992, and finished on December 21, 1993, during repeat cycle 18 . The satellite spatial and temporal sampling corresponds to 1002 ascending and descending passes every 35 days over ground tracks, spaced by $80 \mathrm{~km}$ at the equator. The ESA off-line ocean products (OPR) distributed by Centre ERS d'Archivage et de Traitement (CERSAT) were used in this study.

The 18 cycles of the $92,2500-\mathrm{km}$-long ground tracks located over the region $20^{\circ}-45^{\circ} \mathrm{N}, 45^{\circ}-0^{\circ} \mathrm{W}$ were selected (Figure 1a) to produce sea level anomaly (SLA) data by the conventional repeat track method [e.g., Cheney et al., 1983]. The orbit and most of the altimetric corrections present in the OPRs were used, i.e., the german Processing and Archiving Facilities (D-PAF) precise orbit, the wet tropospheric correction given by the on-board along-track scanning radiometer (ATSR), the dry tropospheric correction and the inverse barometer effect derived from the French Meteorological Office model, the Bent model ionospheric correction, and Cartwright and Tayler [1971] solid lides. New tidal and electromagnetic (EM) bias corrections were used, the University of Texas tidal model [ $M a$ et al, 1994] for geocentric tides and an EM bias of $5.5 \%$ of significant wave height. The EM bias was derived from a global crossover analy sis of ERS 1 data [Gaspar and Ogor, 1994]. Corrected sea surface heights were then resampled along track every $7 \mathrm{~km}$ by cubic spline, and SLA data were obtained by removing the mean profile over the 18 repeat cycles.

In order to reduce the altimetric noise, each SLA profile was low-pass filtered with a Lanczos filter with a cutoff wavelength of $100 \mathrm{~km}$, reducing the SLA rms by $3.1 \mathrm{~cm} \mathrm{rms}$. Moreover, the impact of the satellite orbit error can be lowered by adjusting and removing each SLA profile by a firstorder polynomial, which reduced the SLA variance from 82.8 to $43.6 \mathrm{~cm}^{2}$. These two processings are usually applied for the analysis of altimetric data for mesoscale studies [e.g., $L_{e}$ Traon et al., 19911.

2.1.2. TOPEX/POSEIDON. Launched on August 10, 1992, the T/P mission has a 9.95 -day repeat orbit with a $66^{\circ}$ inclination, which implies a much coarser spatial sampling than ERS 1. There is a $315-\mathrm{km}$ distance between neighboring ground tracks at the equator. On board, two altimeters, TOPEX and POSEIDON, share the same antenna, and POSEIDON is on $10 \%$ of the time [e.g., Fu ef al., 1994]. We used the merged geophysical data records (GDR-M) data set distributed by Archiving, Validation, and Interpretation of Satellite Data in Oceanography (AVISO) for the period beginning on October 4, 1992 (cycle 2), and ending on July 19, 1994 (cycle 67). Data were selected on the same area as the OPR data set (Figure 1b), which represents $29 \mathrm{~T} / \mathrm{P}$ tracks.

The T/P data processing is as for ERS 1. The Joint Gravity Model JGM-2 CNES precise orbit was used, and the following altimetric corrections were applied: TMR radiometer for the wet troposphere, European Center for Medium Range Weather Forecast (ECMWF) for dry troposphere and inverse barometer, 250-km low pass filtered bifrequency ionospheric corrections for TOPEX and Doppler Orbitography and Radiopositioning Integrated by Satellite (DORIS) for POSEIDON for the ionosphere, EM biases for TOPEX and POSEIDON using the BM4 parameterization [Gaspar et al., 1994], University of Texas tidal model for the geocentric tides [Ma et al., 1994], and Cartwright and Tayler [1971] solid tides. SLAs were then calculated as described above for ERS 1. The along-track lowpass filtering and the first-order polynomial removing reduced the raw altimetric SLA variance from $62.4 \mathrm{~cm}^{2}$ to $39.7 \mathrm{~cm}^{2}$, corresponding to a $4.4 \mathrm{~cm}$ rms signal reduction.

\subsection{SEMAPHORE-93 in Situ Data}

2.2.1. Hydrographic data. From mid-June to late November 1993, three hydrographic surveys were performed near the Azores front east of the Mid-Atlantic Ridge as part of the SEMAPHORE-93 experiment. The measurement area spans a $750 \mathrm{~km} \times 500 \mathrm{~km}$ domain, centered on $33^{\circ} \mathrm{N}, 23^{\circ} \mathrm{W}$ (Figure 1a). The data set consists of CTD and XBT measurements collected during three main periods from June to November 1993 (Table 1).

For the comparison with altimetric data, dynamic heights relative to a reference depth of 2000 dbar were calculated. The reference depth $(2000 \mathrm{dbar})$ was the deepest level common to CTD and XBT data, implying that the oceanic circulation below that depth will not be represented in the calculated dynamic height. However, typical velocities at 2000 dbar are only a few centimeter per second [Mïller and Siedler, 1992], so we expect the surface contribution of the missing deep component to be only of order 1 or $2 \mathrm{~cm} \mathrm{rms,} \mathrm{assuming}$ dynamic spatial scales of around $100-200 \mathrm{~km}$. Note also that barotropic oceanic response to changes in wind stress curl can reach a few centimeters [e.g., Gill and Niiler, 1973; Hermann and Krauss, 1989], which will be only partially recorded in the hydrographic data relative to 2000 dbar.

The calculation of dynamic height from XBT temperature profiles requires an estimation of the unknown salinity profiles. This process needs careful attention in the Azores region due to the presence of Mediterranean eddies lenses (meddies) and Mediterranean water north of the Azores front [e.g., Käse and Zenk, 1987; Hebert et al., 1990; Prater and Sanford, 1994]. The experiment domain was split into regions characterized by similar dynamics (north of the front, south of the front, and areas of meddies). Then, linear temperaturesalinity (T-S) relations were deduced from the CTD profiles of each region, at each depth, and for each period. Salinity profiles were deduced from these relations for the XBT casts contained in each region [Jourdan, 1994]. This method was shown to provide accuracy of typically $2 \mathrm{~cm} \mathrm{rms}$ for XBT dynamic height relative to 2000 dbar. For CTD data the accuracy is estimated to be well below $1 \mathrm{~cm} \mathrm{rms}$ [Jourdan, 19941. 
Table 1. SEMAPHORE-93 Hydrographic Data

\begin{tabular}{|c|c|c|c|}
\hline \multirow[t]{2}{*}{ Surveys } & \multirow[t]{2}{*}{ Ships } & \multicolumn{2}{|c|}{ Number of Stations and Collecting Periods } \\
\hline & & XBTs & CTDs \\
\hline Phase I & Alliance ${ }^{a}$ & 70, June 23 to July 1 & 11, June 24 to July 1 \\
\hline Phase 2 & SHOM $^{b}$ & 155 , July 6 to 30 & 49, July 5 to 28 \\
\hline Phase 2 & SHOM $^{\mathrm{b}}$ & 79, Scpt 9 to 13 & \\
\hline Phase 3 & Pr. Stockman ${ }^{\mathrm{c}}$ & & 28 , Oct. 12 to 20 \\
\hline Phase 3 & SHOM $^{\mathrm{b}}$ & 163, Oct. 15 to Nov. 20 & 45, Oct 17 to Nov. 17 \\
\hline Phase 3 & Suroît ${ }^{d}$ & & 46, Oct. 7 to Noy 14 \\
\hline
\end{tabular}

Dates are the beginning and ending of each survey.

${ }^{a} \mathrm{R} / \mathrm{V}$ Alliance is from Supreme Allied Command Atlantic.

b Data were collected by Service Hydrographique et Océanographique de la Marine, Brest, France.

${ }^{c} \mathrm{R} / \mathrm{V}$ Professor Stockman is from Institut Shirshov, Moscow, Russia.

$\mathrm{d}_{R / V}$ Surôt is from Centre National de la Recherche Scientifique, Institut des Sciences de l'Univers, Paris, France.

2.2.2. Surface drifters. Forty-seven 150-m depth drogued drifters (hereinafter referred to as Surdrift drifters) were launched during the hydrographic surveys of phases 1,2 , and 3 (Figure 2). These drifters were designed by the Service Hydrographique et Océanographique de la Marine (SHOM) to precisely follow the geostrophic currents below the mixed layer [e.g., Niiler et al., 1987]. Drifter locations were provided by the Argos satellite tracking system, with a rate of six to eight positions per day. To build the Lagrangian data set (1) spurious positions and undrogued drifters were eliminated; (2) trajectories were resampled every 3 hours using cubic spline interpolation; (3) velocities were calculated by finite differences over 6 hours; and (4) drifter positions and velocities were low-pass filtered with a 3 -day cutoff in order to remove high-frequency oceanic signals, such as tidal and inertial currents. The Surdrift velocity spectrum showed inertial currents 1 order of magnitude smaller than those observed by the Bodega mixed layer drifters [Hernandez, 1995]. These drifters drogued at $20 \mathrm{~m}$ depth were also deployed during SEMAPHORE phase 3. Contrary to the Bodega drifters, the Surdrift velocities did not show any significant coherence with the wind. This a posteriori confirmed that the

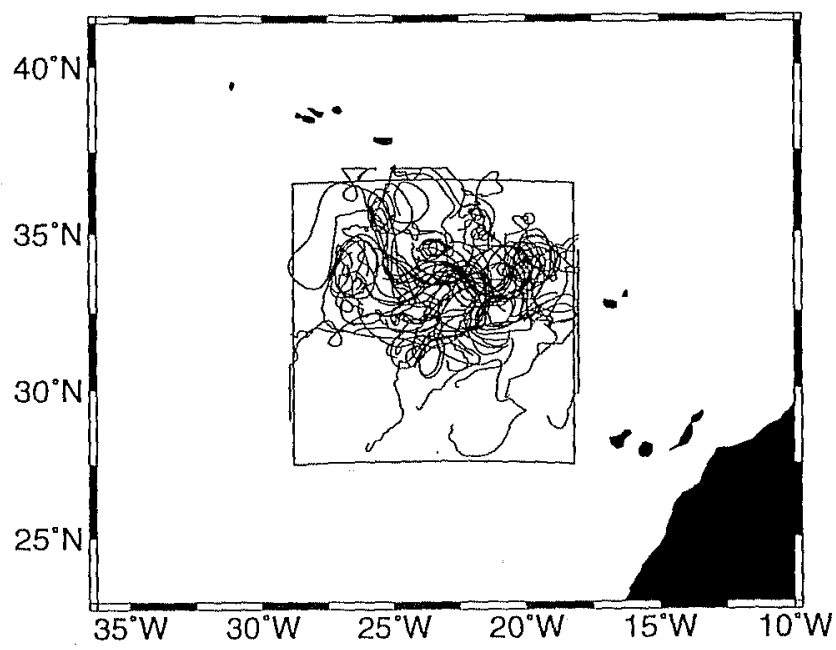

Figure 2. Trajectories of the 47 Surdrift surface floats from July to October 1993. These drifters were drogued at $150 \mathrm{~m}$ depth. The mesoscale circulation, as well as the meandering of the Azores Current system, are clearly shown.
Surdrift drifters mainly measure the geostrophic currents. The error on their velocity measurements (due to wind slippage and unfiltered ageostrophic components) is estimated to be less than $3 \mathrm{~cm} / \mathrm{s}$.

\section{The Mesoscale Circulation Mapping}

\subsection{Methods}

To compare the different signals contained in each type of data, we have mapped the surface dynamic topography using objective mapping techniques $(\mathrm{OA})$. This is particularly useful for irregularly distributed data. Several authors have already used and validated the $\mathrm{OA}$ for synoptic mesoscale circulation mappings, although they contain strong gradient structures or anisotropy [e.g., Mc Williams et al., 1986; Hua et al., 1986; Watts et al., 1989]. OA was performed for the following different data sets: altimetry, hydrography, and surface drifters for three different dates, July 20, September 7, and October 26 , corresponding to the midsurvey date for phases 1,2 , and 3 (see Table 1). The three sets of maps offer synoptic views of the Azores Current meanders. The maps are centered at $33.75^{\circ} \mathrm{N}, 23.25^{\circ} \mathrm{W}$, with a $750 \times 500 \mathrm{~km}$ domain (Figure $1 \mathrm{a}$ ) in order to include the different hydrographic surveys.

The hydrographic data mapping was performed using spacetime objective analysis, associated with the a priori covariance model already used by Le Traon and De Mey [1994] in the same area. The covariance model is given by the function $\mathrm{F}$ :

$$
F(r, d t)=\left[1+b r+\frac{1}{6}(b r)^{2}-\frac{1}{6}(b r)^{3}\right] \mathrm{e}^{-b r} \mathrm{e}^{-(d t / r c t)^{2}}
$$

With constant $b=3.337$, the SLA time correlation radius $r c t$, the time lag $d t$, and the nondimensional radius $r$, which is given as a function of the space lags $d x, d y$, and the space correlation radii $r c x$, rcy as:

$$
r=\sqrt{\frac{d x^{2}}{r c x^{2}}+\frac{d y^{2}}{r c y^{2}}}
$$

As estimed by Le Traon and De Mey [1994], space and time correlation radii $r c x, r c y$, and $r c t$ were chosen equal to $160 \mathrm{~km}$, $200 \mathrm{~km}$ and 20 days respectively. The a priori noise variance on dynamic height measurements was set to $20 \%$ and $5 \%$ of the signal variance for XBT and CTD stations, respectively. 
The signal variance is typically $50 \mathrm{~cm}^{2}$ which gives a noise of about $3 \mathrm{~cm} \mathrm{rms} \mathrm{for} \mathrm{XBTs} \mathrm{and} 1 \mathrm{~cm} \mathrm{rms}$ for CTDs, consistent with the estimated accuracies given in section 2. Note that the OA provides also, a posteriori, an estimation of the mapping error [Bretherton et al., 1976]. The error levels are inversely proportional to the information provided by the observations used by the $\mathrm{OA}$, and they are expressed as percentages of the variance of the analyzed signal, which is given above.

For the altimetric maps we applied suboptimal analysis, as did De Mey and Menard [1989], to reduce the number of data points. We used the band-pass-filtered SLAs, which removed both the altimetric noise and biases due to long-wavelength orbit errors. Combined ERS 1 and T/P mapping was also performed to investigate the improvement provided by the combined two data sets. In order to map the total oceanic surface topography with altimetry, a climatology is usually added to SLA measurements [e.g., Stammer et al., 1991; De Mey, 1994]. We used here the climatology estimated by Robinson et al. [1979] (hereinafter referred to as RBS climatology).

For surface drifters a multivariate analysis was used to construct dynamic height fields from drifter velocities, as described by Le Traon and Hernandez. [1992]. The longitudinal and transverse velocity covariance functions and their spacetime radii were chosen, consistent with those used for the dynamic height covariance functions of (1). All the drifteranalyzed maps were also referenced to the same RBS climatology to obtain comparable fields.

\subsection{Error Maps: Satellite Orbit Influence on the Error Distribution}

The quality of the oceanic circulation maps will depend on the different data distributions. For the hydrographic and drifter maps the error distribution will vary between the different phases, as the instrument position varies. The altimetric error maps are more predictable, since the satellite orbit repetitivity plays the determining role in the space-time sampling of the ocean circulation. The ocean spectrum measured by altimetric data should obey the Nyquist law; that is, only ocean signals with spatial and temporal scales twice as large as the satellite repetitivity and intertrack distance can be detected without aliasing. Thus ERS 1 on its 35-day repeat orbit can only resolve 70-day periods, but it can resolve 160 $\mathrm{km}$ signals between tracks (see Figures $1 \mathrm{a}$ and $1 \mathrm{e}$ ). Note that if isotropy was sought, then along-track data should be $160-\mathrm{km}$ low-pass filtered. The ERS 1 spatial resolution is the same as our chosen mapping decorrelation scales, but the temporal resolution is much larger. This means that some of the higherfrequency signal between 20 and 70 days will not be provided by ERS 1 data. T/P has better temporal resolution (resolving 20-day signals) but, can only resolve $540 \mathrm{~km}$ between tracks at the same latitude (see Figures $1 \mathrm{~b}$ and $1 \mathrm{c}$ ). Thus some of the smaller-scale ocean signals between 200 and $540-\mathrm{km}$ wavelength may not be resolved by T/P. Note that these are upper limits; the resolution can be improved, since the polar orbit satellites offer antisymetric ascending and descending tracks and also subcycles on their samplings. ERS 1 has, in particular, a 16-day subcycle. Also, the oceanic mesoscale structures are usually propagating, and this plays a role in the satellite sampling efficiency. For example, Chassignet et al. [1992] showed that ERS 1 was better at sampling the Gulf Stream evolutions than T/P.
The satellite sampling influence on the mesoscale circulation is shown through the OA error maps (see section 3.1). Figures $3 a$ and $3 b$ show the OA error maps for the ERS 1 and the T/P sampling, which clearly reveal the ground track positions. Histograms of the error values of the phase 1 mapping (Figure 4) confirm that the close ground track spacing of ERS 1 better samples the mesoscale circulation. Note that error levels are lower than 0.3 . The T/P mapping error shows a larger distribution, resulting from the absence of data between ground tracks (Figure 3b), where error level reaches 0.7 . This suggests that in the Azores Current region the ERS 1 smaller spatial resolution is more important than the better temporal resolution of $\mathrm{T} / \mathrm{P}$. Note that for error levels lower than 0.05 we have more T/P data than ERS 1 due to the temporal sampling every 10 days. There is a clear improvement in these error fields when both data sets are combined (Figures $3 \mathrm{c}$ and $4 \mathrm{c}$ ). The error maps for drifter and hydrography depend more on the experimental design and will be discussed in section 3.3 .
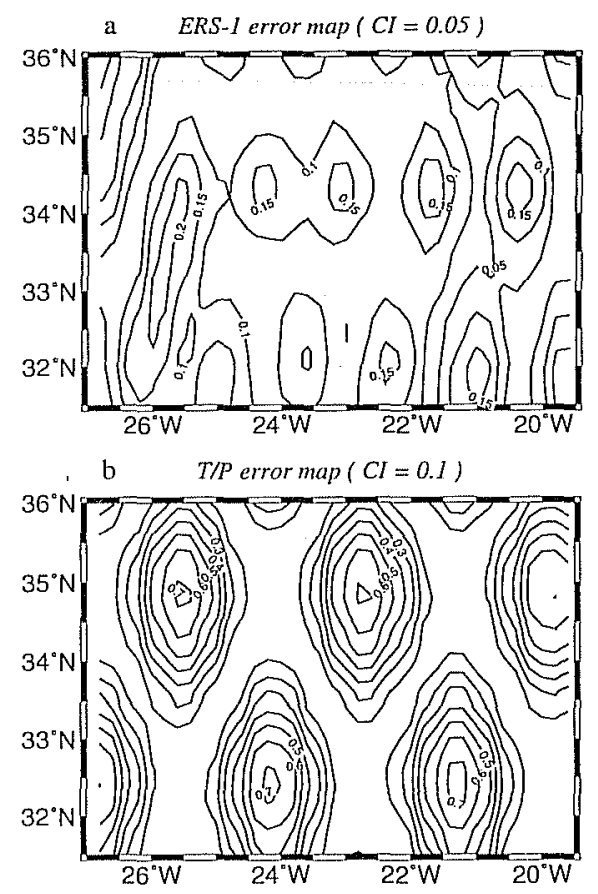

c $\quad E R S-I+T / P$ errormap $(C I=0.05)$

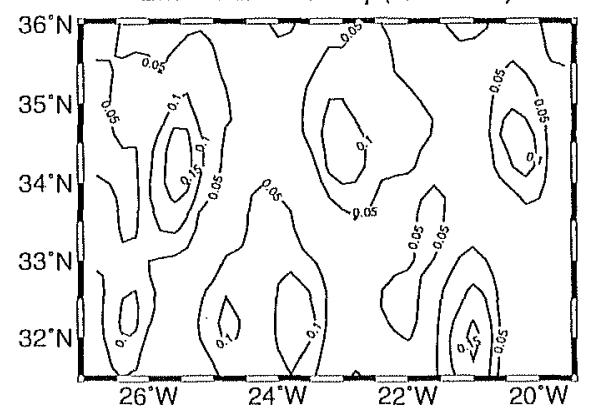

Figure 3. Mapping errors for (a) ERS 1, (b) T/P, and (c) the combined map of both altimetric data sets. Errors are expressed as a percentage of the variance of the estimated signal, i.e., sea level anomaly. The ground track pattern can be seen, with the error maxima located at intertrack areas. The error maxinum reaches 0.7 and 0.20 for T/P and ERS 1 respectively. $\mathrm{Cl}$ is confidence interval. 

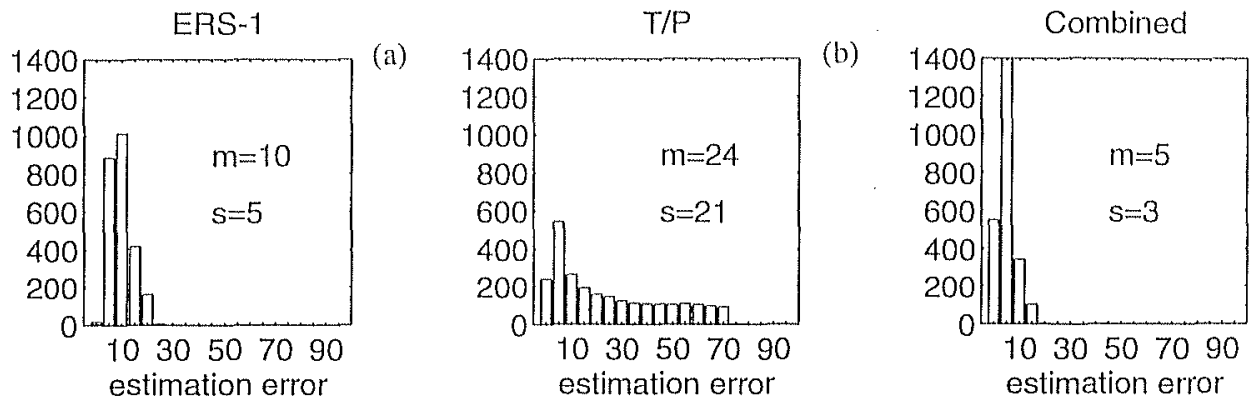

Figure 4. Histograms of the error over the 2501 points of each map, for (a) ERS 1, (b) T/P, and (c) combined data set. Errors are expressed as a percentage of the variance of the estimated signal. Mapping errors from $0 \%$ to $100 \%$ are clivided in $5 \%$ classes. The average $(\mathrm{m})$ and standard deviation (s) values (in percentage) are given for each mapping error distribution.

\subsection{Descriptive Comparisons Between Dynamic Height Maps}

For the three phases the maps of dynamic height anomaly with respect to the spatial mean for the four data sets are presented in Figures 5, 6, and 7, respectively. The purpose of this section is to describe the 4-month evolution of the Azores Current area and the associated eddy field, in particular, to describe and compare in a qualitative manner the mesoscale fields given by the different data sets. The altimetric error maps for phase 1 (Figures 3a-3c) should be kept in mind for reference with the altimetric dynamic heights.

3.3.1. Phase 1: July 20. The mapped hydrography (Figure 5a) shows that the Azores Current is mainly zonal in July, with slight meanders on the edge of five eddies [e.g., Gould, 1985; Käse et al., 1986]. Three anticyclonic eddies are located south of the front, with two cyclonic eddies to the north. Note that in the eastern section there are too few observations (Figure 1c) to describe the fine structure away from the front; these are better recorded by the drifter trajectories (Figure 5b). Although there is an equivalent dynamic height elevation across the front (of about 22 dynamic centimeters (dyn. $\mathrm{cm}$ ), which chiefly corresponds to geostrophic velocities of about $30 \mathrm{~cm} / \mathrm{s}$ ), the front is slightly steeper for the drifters than with the hydrography. Both data sets show an anticyclonic eddy (with traces of Mediterranean water, Eymard et al., manuscript in preparation, 1995) centered on $36^{\circ} \mathrm{N}, 24.5^{\circ} \mathrm{W}$; again, the amplitude is larger on the drifter map. The drifters show a branch of the Azores Current recirculating to the south at $22^{\circ}-23^{\circ} \mathrm{W}$ [e.g., Klein and Siedler, 1989; Le Traon and De Mey, 1994] which is not sampled by the hydrography, as it is shown by the CTD/XBT distribution (Figure 1c). The general shape of the two altimetric maps (Figures $5 \mathrm{c}$ and $5 \mathrm{~d}$ ) is consistent with the in situ map circulation, but the front is less steep and wider by a factor of 2. Some features, such as the eastern anticyclonic eddy, are not sampled by T/P (Figure 5d). However, both altimeters are providing information in the southwest, where there are few in situ data. The large anticyclonic eddy located around $24^{\circ} \mathrm{W}$ has a wide extension to the south as part of the recirculating branch of the jet; this is not well sampled by the in situ data. Clearly, the ERS 1 map contains more small-scale structures than the T/P map. The combined map (Figure 8a) is the closest to the in situ maps. T/P SLAs (Figure 5d) show a strengthening of the anticyclonic meander located on $23.5^{\circ} \mathrm{W}$ in the front and also the south of the northern anticyclonic eddy.
3.3.2. Phase 2: September 7. Toward the end of summer, the Azores Current is still zonal, with less meandering until $22^{\circ} \mathrm{W}$, then it bifurcates north and south of an anticyclonic eddy at $34^{\circ} \mathrm{N}, 20.5^{\circ} \mathrm{W}$, as can be seen in the hydrographic maps (Figure 6a). As in phase 1, more structure is present in the drifter data, in particular, the southern bifurcation passes between an anticyclonic and cyclonic eddy, $150 \mathrm{~km}$ wide, centered on $32.5^{\circ} \mathrm{N}, 23.75^{\circ} \mathrm{W}$ and $32.5^{\circ} \mathrm{N}, 21^{\circ} \mathrm{W}$ respectively, (Figure 6b). Again, the jet is more intense for the drifters than for altimetry or hydrography (Figures 6a, 6c, and $6 \mathrm{~d}$ ). The recirculation branch to the south is part of the large-scale anticyclonic structure on the ERS 1 map (Figure 6c) but is more diffuse on the T/P map (Figure 6d) due to the lack of T/P data in this area (Figure $3 \mathrm{~b}$ ). T/P and ERS 1 both sample the small cyclonic eddy at $32.5^{\circ} \mathrm{N}, 21^{\circ} \mathrm{W}$ seen by the drifters, but only ERS 1 has the resolution to sample the eddy at $35.5^{\circ} \mathrm{N}, 25^{\circ} \mathrm{W}$. Note that the combined altimetric map (Figure $8 \mathrm{~b}$ ) is the closest in representing the drifters' map (Figure 6b). The hydrographic data set only contains XBTs during phase 2 (see Table 1), and the field is clearly oversmooth. The hydrography misses the cyclonic eddy located on $32.5^{\circ} \mathrm{N}, 21^{\circ} \mathrm{W}$, as well as the anticyclonic eddy centered on $35.5^{\circ} \mathrm{N}, 25^{\circ} \mathrm{W}$, which could be due to bad estimations of the XBT salinity profiles, since meddies are located in the same area (Eymard et al,, manuscript in preparation, 1995). These eddies could also have a purely barotropic signal, which could be detected by the drifter velocities and the altimetric SLAs but not by hydrography, although this is unlikely.

3.3.3. Phase 3: October 26. By the end of October the axis at $26^{\circ} \mathrm{W}$ of the Azores Current has migrated $2^{\circ} \mathrm{N}$, the jet then undergoes a large southward meander around a big cyclonic eddy of about 16 dyn. cm centered at $34.5^{\circ} \mathrm{N}, 25^{\circ} \mathrm{W}$. At $33^{\circ} \mathrm{N}$ the current veers to the east, and as in phase 2 , it bifurcates but now farther west at $23^{\circ} \mathrm{W}$ (Figures $7 \mathrm{a}$ and $7 \mathrm{~b}$ ), north around an anticyclonic loop around the eddy centered on $33.5^{\circ} \mathrm{N}, 21.5^{\circ} \mathrm{W}$, south as part of the recirculation branch. Such a mesoscale circulation pattern has already been reported by Käse et al. [1985] during the 1982 Meteor cruise. Note that a cyclonic eddy, $200 \mathrm{~km}$ wide at $32^{\circ} \mathrm{N}, 21.75^{\circ} \mathrm{W}$, is present in both the in situ data maps and the altimeter maps (Figures $7 \mathrm{c}$ and 7d). The front is less intense for $T / P$ than for ERS 1. Once again, the recirculation branch to the south is not clearly seen on the T/P map. The dense spatial coverage of ERS 1 allows us to map the same small-scale structures that are present in the drifter map, in particular north of the current. The combined 

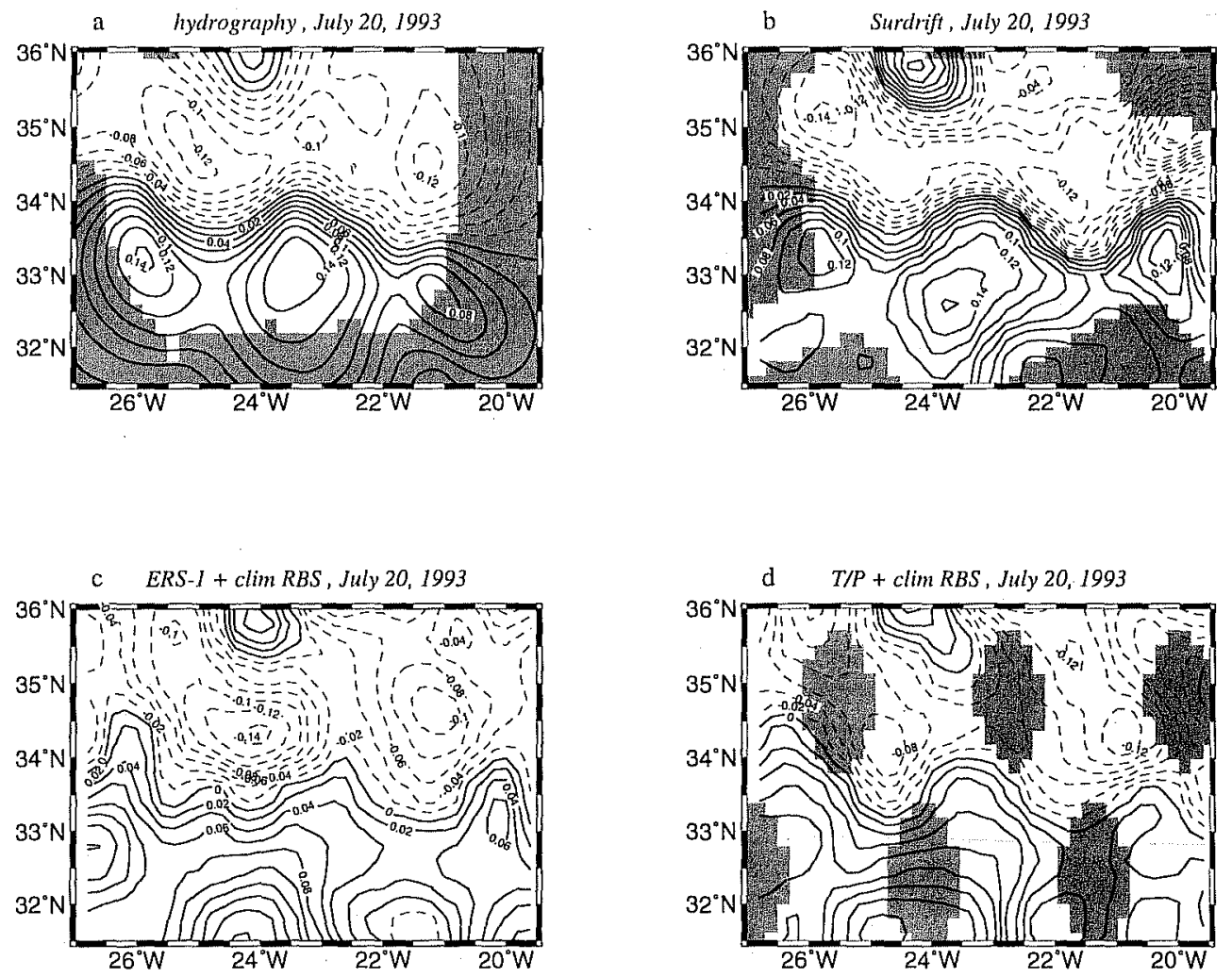

Figure 5. Dynamic height mapping for phase 1 from (a) hydrography, (b) surface drifters, (c) ERS 1 and (d) $\mathrm{T} / \mathrm{P}$ altimetric data sets referenced to the Robinson et al., [1979] (RBS) climatology. Gray shading indicates where the mapping error is larger than 0.4 . The large intertrack areas for T/P are clear. The Azores Current is mainly zonal, and there is a recirculation branch to the south at $23^{\circ} \mathrm{W}$.
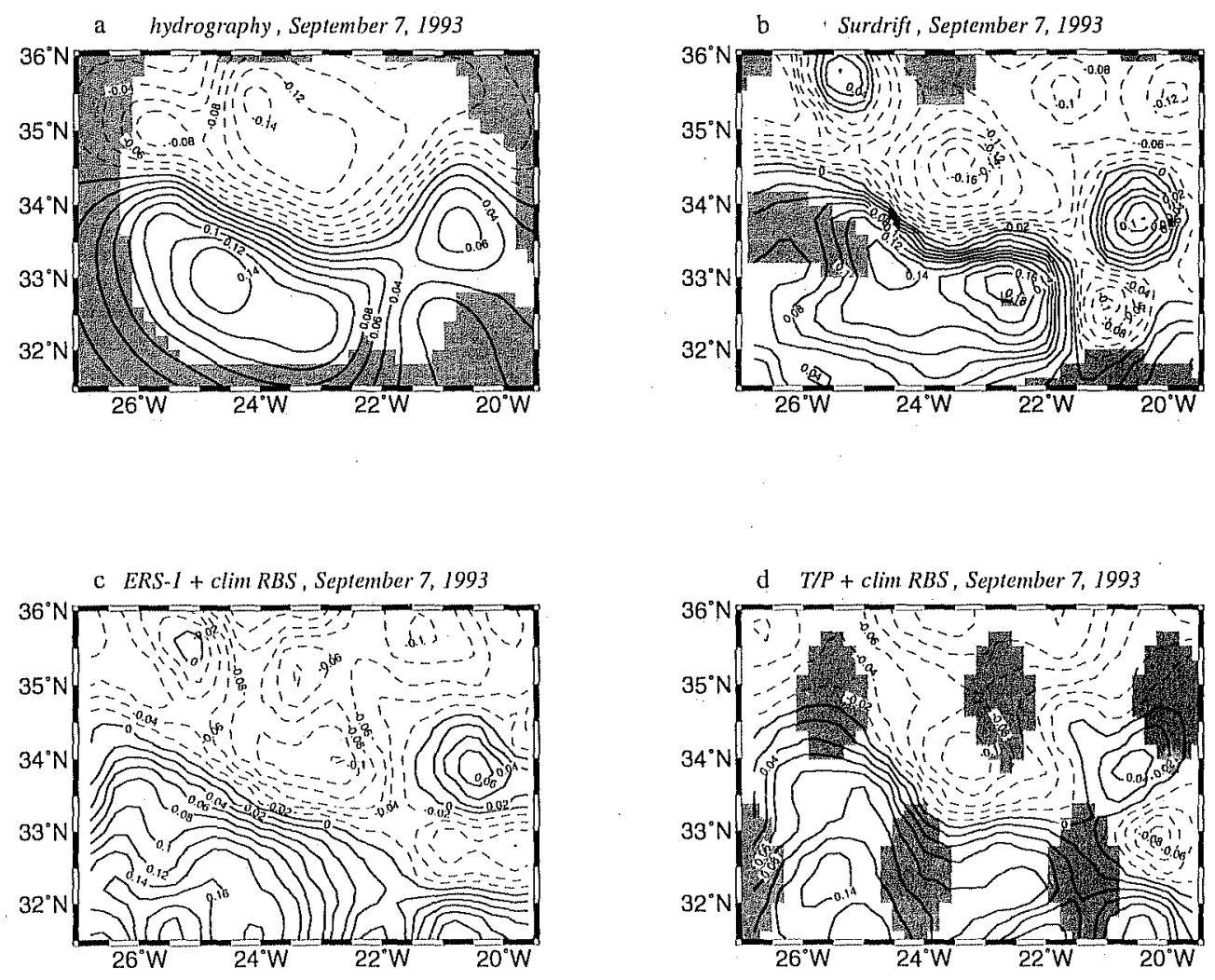

Figure 6. Same as in Figure 5, but for phase 2. The sparse hydrographic data (XBTs) are responsible for the smooth map obtained with hydrography. 

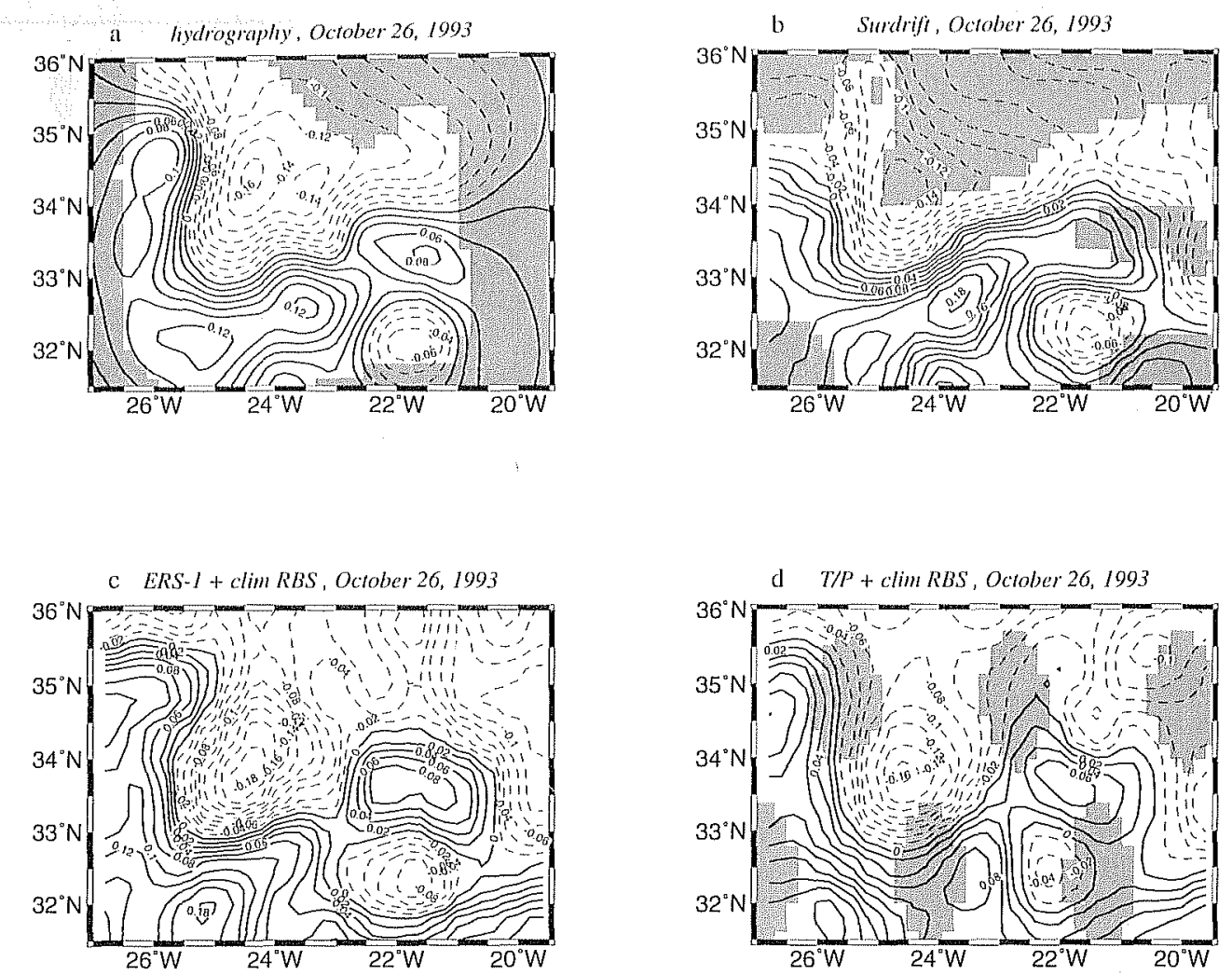

Figure 7. Same as in Figure 5, but for phase 3. The large meandering of the Azores Current is evident, and smaller scales features are clearly seen on the hydrographic map.

map (Figure 8c) is fairly close to the ERS 1 map. In fact, the $T / P$ SLAs constrain the mapping only in the vicinity of the ground tracks (as noted in the error map of Figure 3b); e.g., the southward meridional front at $23.5^{\circ} \mathrm{W}$ in the ERS 1 map is shifted eastward in the combined map.

This qualitative comparison between mesoscale circulation synoptic maps estimated from four types of measurements of the surface ocean clearly shows that the general pattern of the circulation is estimated in a coherent manner by the different data sets. Nevertheless, some aspects of the sampling characteristics and errors of each type of data can already be noticed. Drifters tend to converge on the most intense gradients of the mesoscale circulation [e.g., Hofman, 1985], thus they provide the finest description of the frontal area and the strong eddies. The Azores Current is also well sampled by the hydrographic surveys during phase 3 , but it is poorly sampled during phase 2 (see Figure 1). Consequently, the phase 3 hydrographic mapping contains smaller mesoscale features than the others. Even in this small area of $750 \times 500$ $\mathrm{km}$, the in situ data coverage, varying in both drifter and hydrography data sets from phases 1 to 3 , has a strong influence on the mesoscale circulation mapping, whereas altimetry offers approximately a constant and continuous sampling over the time in the studied area. The main drawback of such sampling is illustrated by the large T/P intertracks, which are not able to describe the small mesoscale features. ERS 1 maps better match the mesoscale features in the in situ data maps. There is a clear improvement when T/P data are added to ERS 1 data to produce the combined maps, which is illustrated by the phase 2 maps. The combined map is then more precise than the XBT map, in comparison to the drifter map. Note also that altimetric data needed to be low-pass filtered in order to remove the instrumental noise. We have applied a $100-\mathrm{km}$ wavelength cutoff, which tends to smooth the frontal dynamic height gradient, in particular, when the front width is less than $70 \mathrm{~km}$ (which often occurs; see, e.g., Maillard and Käse [1989]).

\section{Statistical Comparisons Between Dynamic Height Maps}

A more statistical description of the map differences is given by calculating discrepancies between hydrographic and altimetric maps at each grid point where the hydrographic mapping error is lower than 0.4 (i.e., about $4.5 \mathrm{~cm} \mathrm{rms}$, with a dynamic height variance of about $50 \mathrm{~cm}^{2}$ ). For mapping error larger than this threshold, the areas are shaded gray on the figures, which illustrate the in situ data and altimetric data spatial distribution already discussed in section 3 . Discrepancy rms, regression fits, and correlation coefficients are calculated between the two signals (Table 2). From these we can infer the reliability of the different altimetric data in reconstructing the hydrographic mesoscale field. This is also a way to validate the covariance function and the correlation radii used on the OA (see (1)), since the results should be consistent with section 3.1 .

The results for phases 1 and 2 are rather similar (Table 2). The smoother T/P maps are closer to the mapped hydrography than ERS 1. For these two phases, where we have reasonably large-scale features and wide hydrographic sampling (Figures 1c and $1 \mathrm{~d}$ ), the five T/P tracks in the area seem to produce enough information to build the form of the zonal jet and the 


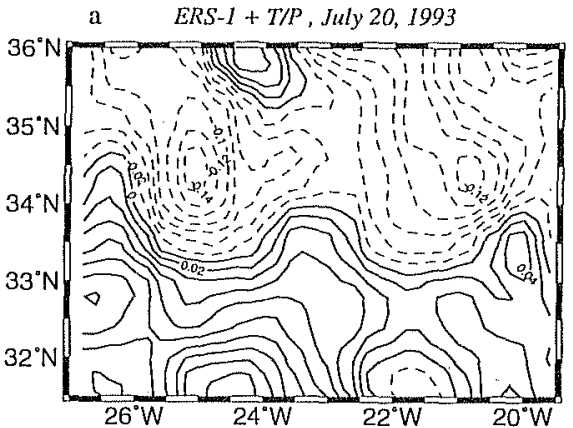

b $\quad$ ERS-I + T/P, September 7,1993

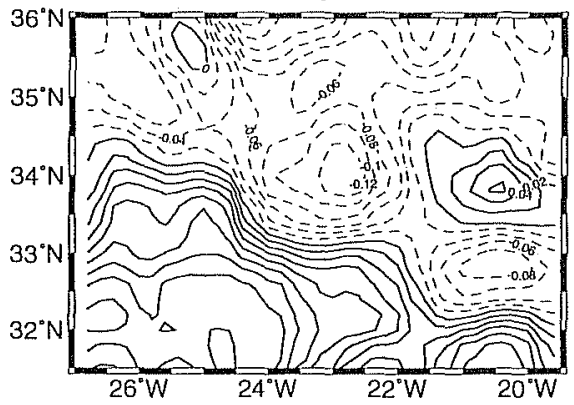

c ERS $-1+T / P$, October 26,1993

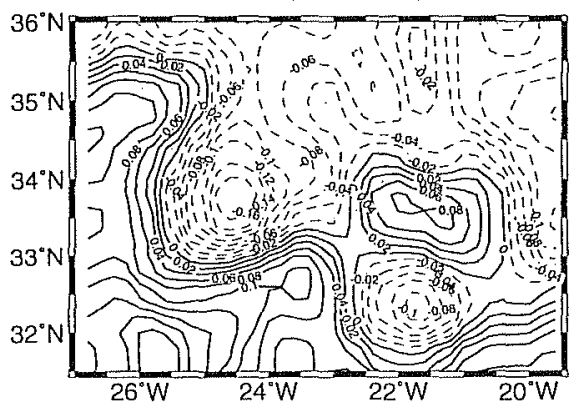

Tigure 8. Dynamic height mapping from combined altimetric data sets for (a) phase 1 , (b) phase 2 , and (c) phase 3 .

mesoscale circulation (Figures 5a and 6a). In these cases the intertrack regions without $\mathrm{T} / \mathrm{P}$ data (Figure $3 \mathrm{~b}$ ) are approximately the same size as the distance between hydrographic stations, and the $\mathrm{OA}$ give similar mesoscale structures. For phases 1 and 2 the combined map discrepancies are between those for ERS 1 and T/P alone (Table 2). Again, this shows that the observations provided by $\mathrm{T} / \mathrm{P}$ are closer to the large-scale field observed by hydrography and that introducing the smaller-scale ERS 1 signal increases the discrepancies. During phase 3, ERS 1 is much closer to the hydrography. Here we have fine-resolution hydrographic data (Figure 1c) which resolve more small-scale structure, particularly in the south and east, which are sampled by the ERS 1 but not by T/P (Figure 7a). Thus the ERS 1 mapping, better matching the hydrography, is better than T/P alone, but in this case the combined field is further improved by the information provided by T/P. Note that comparisons (not shown) using only grid points under the tracks show that T/P has smaller discrepancies and better correlations due to the improved accuracy of the altimeter [e.g., Fu et al., 1994]. The correlation coefficients for the three types of altimeter mapping are all high, around $0.8-0.9$, and show that altimetric data are able to construct the features of the mesoscale circulation measured by hydrography. Note that the lower regression fit coelficients of $0.6-0.8$ may be due to the
Table 2. The rms of the Discrepancies Between Hydrographic and Altimetric Dynamic Height Maps and The Slopes of the Regression Fits and Correlation Coefficients for Each Phase

\begin{tabular}{lccc}
\hline $\begin{array}{c}\text { Compared Altimetric } \\
\text { Maps }\end{array}$ & $\begin{array}{c}\text { Discrepancies, Regression Fit } \\
\text { cm rms }\end{array}$ & $\begin{array}{c}\text { Correlation } \\
\text { Coefficient }\end{array}$ \\
\hline & Phase J & & \\
ERS 1 & 5.0 & 0.57 & 0.84 \\
T/P & 4.4 & 0.64 & 0.88 \\
Combined ERS 1 + T/P & 4.6 & 0.63 & 0.87 \\
& Phase 2 & & \\
ERS 1 & 4.9 & 0.70 & 0.84 \\
T/P & 4.6 & 0.70 & 0.87 \\
Combined ERS 1 + T/P & 4.6 & 0.74 & 0.85 \\
& Phase 3 & & \\
ERS 1 & 4.2 & 0.88 & 0.88 \\
T/P & 4.6 & 0.72 & 0.84 \\
Combined ERS 1 + T/P & 3.9 & 0.84 & 0.90 \\
\hline
\end{tabular}

addition of the smoother climatology to the altimetric maps. Dynamic gradients contained in the altimetric maps are weaker than gradients present in the hydrography, which is also apparent by the total variances of about $60 \mathrm{~cm}^{2}$ and $40 \mathrm{~cm}^{2}$ for hydrography and altimetry, respectively.

The good T/P scores for phases 1 and 2 were not expected by the mapping error distribution (Figure $3 \mathrm{~b}$ ). This may be sensitive to our choice of correlation radii in the $O A$ covariance functions of (1). We tested this in turn by reducing (1) the spatial radii to $100 \mathrm{~km}$ and (2) the temporal radius to 10 days and (3) by increasing the temporal radius to 35 days. The rms discrepancy and averaged mapping errors (as given by the OA) were calculated over the three phases for the altimetric maps (Table 3). The ERS 1 discrepancies are always larger than $T / P$, except for the $100-\mathrm{km}$ correlation radius case, where the estimates between tracks are calculated with fewer observations. Moreover, the combined map results are better than the separate satellite mapping results, except for the 35 day correlation radius case. The mean mapping error levels (percentages in parenthesis in Table 3) showed a large variation when the correlation radii were changed, which was not reflected in the discrepancy values. As expected from Figure $3 b$, the mean error levels for $\mathrm{T} / \mathrm{P}$ are larger than for ERS 1, except when the temporal radius of 10 days is used.

The difference in discrepancies may result from the difference in spacescales and timescales of the mesoscale

Table 3. Influence of the Correlation Scales

\begin{tabular}{lccc}
\hline Correlation Radii & ERS 1 & T/P & Combined \\
\hline $160,200,20$ & $4.7(9.4)$ & $4.5(24.3)$ & $4.4(5)$ \\
$100,100,20$ & $4.8(21.3)$ & $4.9(45.4)$ & $4.6(12.7)$ \\
$160,200,10$ & $4.9(32.7)$ & $4.7(30.8)$ & $4.5(13.2)$ \\
$160,200,35$ & $4.7(4.6)$ & $4.3(19.6)$ & $4.4(2.9)$ \\
\hline
\end{tabular}

Numbers for the three types of altimetric maps are the averaged (over the three phases) rms discrepancies (in centimeters) between hydrographic and altimetric maps. Numbers in parenthesis are the mean quadratic mapping error values (in percentage).

"Space and time correlation radii were used in the objective mapping techniques. The first number, rex, and the second number, rey, are in kilometers, The third number, ret, is in days. See equation (2). 
variability contained in altimetric and hydrographic data, For example, the phase 2 hydrographic mapping (Figure 6a) shows spatial scales of the order of $200 \mathrm{~km}$ or more, resulting from the hydrographic data spacing of about $80 \mathrm{~km}$ (Figure Id), but the larger XBT a priori error is also included in the OA which increases the smoothing. Thus the hydrography is oversmoothed, and there are higher discrepancies with the ERS 1 data. Low discrepancies with the T/P mapping are not surprising because both data sets only contain scales larger than $150 \mathrm{~km}$. In general, the shorter scales contained in the ERS 1 maps, and thus the combined maps increase the discrepancies with the hydrographic maps, except for the phase 3 mapping, where the hydrographic data set offers shorter scales. The mean error mapping levels would give more accurate discrepancy variances if the hydrographic data gave a better representation of the oceanic mesoscale circulation.

As described in section 2.1 , because of the lack of precise geoid, only variations of sea surface topography relative to a mean (i.e., SLAs) can be precisely measured by altimetry. We have used above the RBS climatology to represent the mean sea surface topography, but the mapping comparisons may be contaminated by the nonrepresentativity of this climatological field at the seasonal and annual timescales, in comparison with our two different satellite data sets. Both altimetric data sets have a 20 -month mean removed but corresponding to shifted periods (see section 2.1), implying different contributions from the interannual ocean variability. Moreover, the mean altimetric profiles for T/P and ERS 1 tracks are not statistically equivalent, since they are calculated with 66 and 18 cycles, respectively. In particular, ERS 1 mean is not very well constrained and aliases the high-frequency signals (periods lower than 70 days). In addition, the climatology, estimated with hydrographic measurements not regularly spaced over several decades, should have different averaging lengthscales and timescales. These slightly different means may also contribute to the difference in discrepancies.

To eliminate difference in the temporal mean, a direct comparison between altimetric and hydrographic measurements can be done through a time difference scheme. Thus we have compared time differences of altimetric maps to time differences of hydrographic maps as follow: phase 3 minus phase 1 , phase 2 minus phase 1 , and phase 3 minus phase 2 . As before, only grid points where the hydrographic mapping error was low were selected to estimate the discrepancies.

Table 4 shows the rms of the time difference discrepancies, the regression fit slope coefficients, and the correlation coefficients between the two time difference signals. Comparisons between phase 3 and phase 1 show the largest discrepancies between hydrography and altimetry. The dynamics show the largest change between July and midOctober (Figures 5 and 7); furthermore, the hydrographic data distribution is not equivalent between these two phases (see Figure 1). These large discrepancies are affected by the poor comparisons between ERS 1 at phase 1 and also T/P and hydrography at phase 3 (see Table 2). Discrepancies between phase 2 and phase 1 are quite low. As explained above, T/P mapping better matches the spatial scales contained in phase 1 and 2 hydrographic data, and the dynamics remain fairly stable. However, the correlation and regression fits are high $(0.7-0.9)$ over all the comparisons and larger than in the direct
Table 4. Mapping Comparisons for Time Differences

\begin{tabular}{|c|c|c|c|}
\hline $\begin{array}{c}\text { Difference of Altimetric } \\
\text { Maps }\end{array}$ & $\begin{array}{l}\text { discrepancies, } \\
\text { cm rms }\end{array}$ & Regression Fit & $\begin{array}{l}\text { Correlation } \\
\text { Coefficient }\end{array}$ \\
\hline \multicolumn{4}{|c|}{ Phase 3 Minus Phase I } \\
\hline ERS I & 4.3 & 0.75 & 0.85 \\
\hline $\mathrm{T} / \mathrm{P}$ & 4.7 & 0.69 & 0.82 \\
\hline Combined ERS 1 and $\mathrm{T} / \mathrm{P}$ & 3.4 & 0.86 & 0.91 \\
\hline \multicolumn{4}{|c|}{ Phase 2 Minus Phase I } \\
\hline ERS 1 & 4.0 & 0.76 & 0.78 \\
\hline $\mathrm{T} / \mathrm{P}$ & 2.8 & 0.94 & 0.90 \\
\hline Combined ERS 1 and T/P & 3.1 & 1.08 & 0.91 \\
\hline \multicolumn{4}{|c|}{ Phase 3 Minus Phase 2} \\
\hline ERS 1 & 3.4 & 0.95 & 0.89 \\
\hline $\mathrm{T} / \mathrm{P}$ & 4.7 & 0.80 & 0.79 \\
\hline Combined ERS 1 and $T / P$ & 3.5 & 1.01 & 0.90 \\
\hline
\end{tabular}

See Table 2 for parameters.

map-to-map comparisons (see Table 2). The time difference discrepancy variances give twice the direct discrepancy variances between hydrography and altimetry, thus we can estimate these discrepancies to be less than 3 and $3.3 \mathrm{~cm} \mathrm{rms}$ for ERS 1 and T/P respectively. The combination of the two altimetric data sets shows slope regression fits of about 1 , meaning that we have equivalent variance levels between hydrography and altimetry over the two maps. This demonstrates that the previous discrepancies were mostly due to error in the temporal means. Moreover, if we express the discrepancy variances relative to the hydrographic variance (i.e., $50 \mathrm{~cm}^{2}$ ), we obtain values of $18 \%, 23 \%$, and $11.5 \%$ for ERS $1, T / P$, and the combined map in the case phase 3 minus phase 1 (which is the more representative case because of the smooth phase 2 map), respectively, in Table 4 . Note that these values are closer to the expected mean mapping error levels presented in Table 3 (percentages in parenthesis), which confirms that the use of the climatology creates a bias on the direct discrepancy variances.

These time difference comparisons show that the altimetry provides enough information to reconstruct the variable mesoscale field as measured by hydrography. Furthermore, the combination of the altimetric data sets clearly improves the mapping, with discrepancies relative to hydrography lower than $2.5 \mathrm{~cm} \mathrm{rms}$, which is approximately the level of uncertainty about the missing deep circulation in the hydrography and the hydrography accuracy (see section 2.2 ).

\section{Summary and Conclusions}

During the second half of 1993, while ERS 1 and T/P were flying simultaneously, the SEMAPHORE experiment was conducted in the Azores Current vicinity. Intensive hydrographic surveys and Lagrangian in situ measurements provided a good description of the mesoscale surface circulation. This was a timely opportunity to evaluate the estimation of the mesoscale circulation from the two different sets of altimetric data and to compare the results with the in situ data measurements.

Mapping techniques using $\mathrm{OA}$ provided an estimation of the surface topography or dynamic height field, representing the geostrophic circulation for each different data set. OA also 
provides a mapping error field related to the a priori error of each type of data and their space and time distribution in the $500 \times 750-\mathrm{km}$ area. The qualitative comparison for the three phases between the four types of maps allowed us to describe the Azores Current evolution from July to the end of October 1993 and also shows the good agreement between altimetric maps and corresponding drifter and hydrographic maps. The major features of the mesoscale contained in the hydrographic data (e.g., front shape, large eddies) are clearly reproduced in both the ERS 1 and T/P maps. Many smaller-scale structures that were not sampled by the widely spaced hydrographic measurements were evidenced by the surface drifter trajectories. These smaller-scale features were generally represented in the ERS 1 maps and thus in the combined maps. This is an encouraging result for further mesoscale studies that use the combined data, e.g., for assimilation experiments.

More quantitatively, the regression fits between hydrography and altimetry were calculated for all points close to the hydrograpic stations, with values of around $0.6-0.7$. Given the good qualitative agreement, these regressions are lower than expected. However, although the positions of eddies and meanders are fairly well represented, the mapped altimeter data show a weaker Azores Front than in the mapped drifter and hydrographic data. This is mainly due to the use of a smooth climatology to reference the altimetric maps. The climatology is not a good representation of the mean profiles removed from T/P or ERS 1, which are calculated over slightly different time intervals with a different number of points, so the means are statistically and temporally distinct. This clcarly reveals the need for a good high-resolution mean sea surface in order to optimally adjust and combine the different altimetric data sets.

Once the mean fields from each data set have been removed, the correlation for time differences is good: typically, 0.8-0.9 with regression fits not significantly different from 1 . In comparison to the hydrographic data, T/P mapping is almost as good as ERS 1 mapping which was rather unexpected, since the ERS 1 space-time sampling is better suited for the mesoscale. For example, Morrow and De Mey [this issue] have shown that in the same area the assimilation of ERS 1 data better constrains the model forecast than $T / P$. This may reflect, however, the fact that the signal as mapped by the hydrography does not contain the small-scale signals. T/P and ERS 1 combined provide better results, although the improvement is not as large as expected, probably for the same reason. The accuracy of the combined altimetric maps is, however, only $2-3 \mathrm{~cm} \mathrm{rms}$, which is comparable or even better than the accuracy of surface dynamic topography maps obtained from hydrographic surveys.

Acknowledgments. The SEMAPHORE has, for its mesoscale component, been designed, funded, and carried out by $S H O M$, the French Navy Hydrographic and Oceanographic Service. We thank, in particular, Yves Camus who was responsible for the operational part of the experiment. This study could be realized less than 1 year after the oceanographic campaign, thanks to the work of the ROME Group in Toulouse, in particular, Didier Jourdan and Sophic Baudel, who processed the hydrographic data. We also thank Joel Dorandeu for the altimetric data processing. This study was supported by SHOM (contract SHOM-CLS 94183). Fabrice Hernandez was also partly funded by a Ph.D. CIFRE grant and Rosemary Morrow by a CNRS/SHOM convention.

\section{References}

Bretherton, F.P., R.E. Davis, and C.B. Fandry, A technique for objective analysis and design of oceanographic experiments applied to MODE-73, Deep Sea Res., 23, 559-582, 1976.

Cartwright, D.E., and R.J. Tayler, New computations of the tidegenerating potential, Geophys. J. R. Astron. Soc., 23, 45-74, 1971.

Chassignet, E.P., W.R. Holland, and A. Capontondi, Impact of the altimeter orbit on the reproduction of oceanic rings: Application to a regional model of the Gulf Stream, Oceanol. Acta, 15, (5), 479-490, 1992.

Cheney, R.E., J.G. Marsh, and B.D. Becley, Global mesoscale variability from collinear tracks of Seasat altimeter data, J. Geophys. Res., 88, 4343-4354, 1983.

De Mey, P., Optimal interpolation in a model of the Azores Current in 1986-88, in Global Environment Change, NATO ASI Ser., Ser. I, pp 85-106, Springer-Verlag, New York, 1994.

De Mey, P., and Y. Ménard, Analysis and assimilation of altimeter residuals and in situ measurements in the POLYMODE area, $J$, Geophys. Res., 94, 6221-6231, 1989.

Fu, L.-L., E.J. Christensen, C.A. Yamarone Jr., M. Lefevre, Y. Ménard, M. Dorrer, and P. Escudier, TOPEX/POSEIDON mission overview, J. Geophys. Res., 99, 24,369-24,381, 1994.

Gaspar, P., and F. Ogor, Estimation and analysis of the sea state bias of the ERS 1 altimeter, technical report, Collecte Localisation Satellites, Toulouse, France, 1994.

Gaspar, P., F. Ogor, P.-Y. Le Traon, and O.Z. Zanife, Estimating the sea state bias of the TOPEX and POSEIDON altimeters from crossover differences, J. Geophys. Res., 99, 24,981-24,994, 1994.

Gill, A.E., and P.P. Niiler, The theory of the seasonal variability in the ocean, Deep sea Res., 20, 141-177, 1973.

Gould, W.J., Physical oceanography of the Azores Front, Prog. Oceanogr., J4, 167-190, 1985.

Hallock, Z.R., J.M. Mitchell, and J.D. Thompson, Sea surface topographic variability near the New England Seamounts: An intercomparison among in situ observations, numerical simulations, and Geosat altimetry from the Regional Energetics Experiment, $J$. Geophys. Res., 94, 8021-8028, 1989.

Hebert, D., N. Oakey, and B. Ruddick, Evolution of a Mediterranean salt lens: Scalar properties, J. Phys. Oceanogr, 20, 1468-1483, 1990.

Hermann, P., and W. Krauss, Generation and propagation of annual Rossby waves in the North Atlantic, J. Phys. Oceanogr., 19, 727$744,1989$.

Hernandez, F., Comparison et combinaison des données altimétriques et des données de flotteurs Lagrangiens: Application à la campagne Semaphore, Ph.d. thesis, 340 pp., Toulouse Univ., France, 1995.

Hofmann, E. E., The large-scale horizontal structure of the Antartic Circumpolar Current from FGGE drifters, J. Geophys. Res., 90, 7087-7097, 1985

Hua, L.B., J.C. McWilliams, and W.B. Owens, An objective analysis of the POLYMODE Local Dynamics Experiment, II, Streamfunction and potential vorticity fields during the intensive period, J. Phys. Oceanogr., 16, 506-522, 1986.

Jourdan, D., Etude des Conditions Hydrologiques dans le Bassin Canaries-Açores, final report, Services Hydrographiques et Océanographiques de la Marine / Centre Militaire d'Océanographie / Bureau de Recherche SHOM-Météo, Toulouse, France, 1994.

Käse, R.H., and W. Zenk, Reconstructed Mediterranean salt lens trajectories, J. Phys. Oceamogr., 17, 158-163, 1987.

Käse, R.H., W. Zenk, T.B. Sanford, and W. Hiller, Currents, fronts, and eddy fluxes in the Canary Basin, Prog. Oceanogr., 14, 231-257, 1985.

Käse, R.H., J.F. Price, P.L. Richardson, and W. Zenk, A quasi-synoptic survey of the thermocline circulation and water mass distribution within the Canary Basin, J. Geophys. Res., 91, 9739-9748, 1986.

Klein, B., and $G$. Siedler, On the origin of the Azores Current, $J$. Geophys. Res., 94, 6159-6168, 1989.

Le Trion, P..Y., Time scales of mesoscale variability and their relationship with spatial scales in the North Atlantic, J. Mar. Res., 49, 467-492, 1991.

Le Traon, P.-Y,. and P. De Mey, The eddy field associated with the Azores Front east of the Mid-Allantic Ridge as observed by the Geosit altimeter, J. Geophys. Res, 99, 9907-9923, 1994.

Le Traon, P.-Y., and $F$. Hernandez, Mapping the oceanic mesoscale circulation: Validation of satellite altimetry using surface drifters, $J$. Atmos. Oceanic Technol, 9, 687-698, 1992. 
Le Traon, P.-Y., C. Boissier, and P. Gaspar, Analysis of errors due to polynomial adjustments of altimeter profiles, I. Aimos. Oceanic Technol., 8, 385-396, 1991.

Le Traon, P.-Y., P. Gaspar, F. Bouyssel, and H. Makhmara, Using Topex/Poseidon to enhance ERS I data, I. Atmos. Oceanic Technol, $12,161-170,1995$

Ma, X.C., C.K. Shum, R.J. Eanes, and B.D. Tapley, Determination of ocean tides from the first ycar of TOPEX/POSEIDON altimeter measurements, I. Geophys. Res, 99, 24,809-24,820, 1994.

Maillard, C., and R.H. Kiise, The near surface flow in the subtropical gyre south of the Azores, J. Geophys. Res., 94, 16,133-16,140, 1989

McWilliams, J.C., W.B. Owens, and B. L. Hua, An objective analysis of the POLYMODE Local Dynamics Experiment, I, General formalism and statistical model selection, J. Phys. Oceanogr., 16, 483-504, 1986.

Morrow, R., and P. De Mey, Adjoint assimilation of altimetric, surface drifter and hydrographic data in a quasi-geostrophic model of the Azores Current, J. Geophys. Res, this issue.

Miiller, J.T., and G. Siedler, Multi-year time series in the eastern North Atlantic Ocean, J. Mar. Res., 50, 63-98, 1992.

Niiler, P.P., R.E. Davis, and H.J. White, 1987. Water-following characteristics of a mixed layer drifter. Deep-sea Res., Part A, 23, 559-582.

Prater, M.D., and T.B. Sanford, A Meddy off Cape St. Vincent, I, Description, J. Phys. Oceanogr., 24, 1572-1586, 1994.

Richardson, P.L., Eddy kinetic energy in the North Atlantic Ocean from surface drifters, J. Geophys. Res, 88, 4355-4367, 1983

Robinson, M., R. Bauer, and E. Schroeder, Atlas of North AtlanticIndian Ocean monthly mean temperatures and mean salinities of the surface layer, Dep. of the Navy, Washington, D.C., 1979
Stammer, D., H.-H. Hinrichsen, and R.H. Kisse, Can Meddies be detected by satellite altimetry?, J. Geophys. Res, 96, 7005-7014, 1991.

Wakker, K.F., M.C. Naeje, E. Wisse, R. Scharroo, P. Visser, and B. Ambrosius, Geosat and ERS I radar altimetry over the North Alantic, Adv, Space Res., 13(11), 305-314, 1993

Watts, D.R., K.L. Tracey, and A.I. Friedlander, Producing accurate maps of the Gulf Stream thermal front using objective analysis, $J$. Geophys. Res, 94, 8040-8052, 1989.

Willebrand, J., R.H. Käse, D. Stammer, H.-H. Hinrichsen, and W. Krauss, Verification of Geosat sea surface topography in the Gulf Stream extension with surface drifting buoys and hydrographic measurements, J. Geophys. Res., 95, 3007-3014, 1990.

Zlotnicki, V., G. Siedler, and B. Klein, Can the weak surface currents of the Cape Verde frontal zone be measured with altimetry? $J$. Geophys. Res., 98, 2485-2493, 1993.

F. Hernandez and P.-Y. Le Traon, Space Oceanography Group, Collecte Localisation Satellites, 18 Avenue Edouard Belin, 31055 Toulouse Cedex, France. (e-mail hermand@thor.cnes.fr; letraon@atlas.cnes.fr)

R. Morrow UMR 39, Groupe de Recherche de Géodésie Spatiale, 14 Avenue Edouard Belin, 31055 Toulouse, France. (e-mail: morrow@nanook.cst.cnes.fr)

(Received March 15, 1995; revised July 31, 1995; accepted July 31, 1995.) 